\title{
Los Austrias y las ceremonias alrededor de la muerte del rey, ritual y simbología
}

\section{The Habsburg's kings in Spain and the ceremonies around the king's death, rites and symbols}

\author{
María V. Gómez Requejo ${ }^{1}$ \\ Universidad Europea de Madrid \\ mar.gomez@telefonica.net
}

Recepción: 17/05/16 Revisión: 22/05/16 Aceptación: 28/05/16 Publicación: 01/06/16

http:// (página web de inclusión del artículo)

\section{Resumen:}

Las ceremonias que se tenían lugar cuando se producía el fallecimiento de un monarca de la casa de Austria, tanto las pre como las post mortem, eran el vehículo de un lenguaje simbólico cargado de representaciones y emblemas que le recordaban al súbdito tanto el poder del rey muerto como el que iba a tener su sucesor y asimismo ponían de manifiesto la unión de la dinastía con la Iglesia Católica.

Enfermedad, muerte y exequias se convierten, con estos monarcas, en un espectáculo fastuoso que requiere escenografía, actores, vestuario, guion y un público -los súbditos- del que se busca una participación ya sea consciente y activa o pasiva, como mero espectador, pero en todo caso necesario para que el espectáculo cumpla su objetivo: persuadir del poder real.

Palabras clave: Ceremonial, rito, símbolos, muerte, exequias, funerales.

\section{Abstract}

The ceremonies around the death of a Habsburg king in Spain, where the vehicle to a symbolic language, full of representations and emblems, used to remind to his loyal subjects not only the power of the dead king and the one his heir and successor was going to hold, but also the relationship between the dynasty and the Roman Catholic Church.

With the Habsburg's, the illness, death and exequies of the monarch were converted into a sumptuous show that needed: a set, actors, lavish costumes, script and audience -the loyal subjects- to which audience participation, whether it be active or passive, was essential to fulfill its objective: to be persuaded of the king's power.

Keywords: Ceremonies, rites, symbols, exequies, funerals.

\section{Sumario}

1. Introducción

2. Los Austrias y las ceremonias entorno a la muerte del rey: ceremonial y simbología

\footnotetext{
${ }^{1}$ Licenciada en Derecho, UAM; Grado en Protocolo, UMH; profesora en la Universidad Europea de Madrid, doctorando en Derecho en la UNED.
} 
2.1. Hitos entorno a la muerte: agonía, fallecimiento, entierro y honras:

2.2. Ab ultima aeternitas

3. Conclusiones

4. Bibliografía

\section{Sumario}

1. Introduction

2. Austrias and ceremonies around the death of the king, ceremonial and symbolism

2.1. Milestones around the death agony, death, burial and honors:

2.2. Ab ultima aeternitas

3. Conclusions

4. Bibliography

"Se impone la deslumbrante presencia de la realeza, proclamando su carácter sagrado, capaz de subyugar la mirada de sus vasallos hasta en la hora de la muerte por medio de un espectáculo fastuoso" (Varela, 1990:63).

\section{INTRODUCCIÓN}

Hay en la muerte del rey un afán de perdurar, de perpetuarse en el tiempo. La idea de pasar a la posteridad y "encontrar un lugar en la Historia (...) puesto que solo eso le permitirá trascender la fugaz existencia y alcanzar, a través de la gloria, la inmortalidad" (Pina Polo, 2004:145). Con esta idea en mente se preparan una serie de ceremonias que tendrán lugar en tres espacios: el palacio, la calle y la iglesia. Ceremonias en las que arquitectura efímera, signos, símbolos y atuendos ayudarán a perpetuar la presencia del rey; darán fe del poder de la dinastía y la fidelidad de la nobleza y constatarán el compromiso del fallecido y su sucesor con la iglesia. Además, la contemplación de este aparato ceremonial, establecerá un lazo entre el súbdito que lo observa y el rey muerto, que está presente a través de esta parafernalia.

En esa búsqueda de la gloria -la que el diccionario de la lengua define como "reputación, fama y honor extraordinarios que resultan de las buenas acciones y gran-des cualidades de una persona"- de perdurar en el tiempo dejando algún vestigio de sí mismo para el futuro, se hacía necesario poner de manifiesto los logros del fallecido que pasaban al patrimonio histórico de la dinastía (Pina Polo, 2004). Esa puesta en común se hará a través de las ceremonias y en concreto de sus decorados, dentro de los que destaca el túmulo; una obra de arquitectura efímera, en la que se recogen inscripciones honoríficas, jeroglíficos y 
enigmas, alusivos al fallecido, centrándose en sus hazañas, ya sean reales o magnificadas, y las de insignes figuras de quienes le precedieron, a quienes el rey muerto no podía desmerecer, ya que el objetivo era aumentar ese prestigio heredado para, a su vez, dejarlo en herencia al sucesor.

El funeral se convierte así en la expresión de la preeminencia de la dinastía y la adhesión de la nobleza entorno al rey muerto y al rey vivo, además de resaltar los lazos con la iglesia, sancionados en Trento, en el que el rey tenía un papel importantísimo como defensor de la fe en la lucha contra el protestantismo (Martínez Gil, 2000). Estas expresiones proporcionaban estabilidad y continuidad a la monarquía, que estaba garantizada por la presencia del nuevo rey, su sucesor, heredero -a su vez- de ese pasado glorioso.

A través de las ceremonias fúnebres comprobamos la utilización del protocolo como instrumento de comunicación al servicio de la clase dominante. Todas estas ceremonias "no hacían sino reforzar la conciencia de grupo y la manifestación de las dependencias sociales" (Martínez Gil, 2000:205). La muerte afianzaba seguridades.

\section{LOS AUSTRIAS Y LAS CEREMONIAS ALREDEDOR DE LA MUERTE DEL REY, RITUAL Y SIMBOLOGÍA}

\subsection{Hitos entorno de la muerte: agonía, fallecimiento, entierro y honras}

\subsubsection{Agonía y fallecimiento}

El rey se ha preparado para la buena muerte, la que tiene como fin la salvación, para ello estaban las técnicas del ars moriendi ${ }^{2 ;}$ incluso había realizado sus previsiones testamentarias relacionadas con el tratamiento de su cadáver, la mortaja que lo cubriría y las misas que deberían decirse en su memoria. En este sentido Fray Diego de Yepes (confesor de Felipe II) nos relata que este rey "Fue enterrado o colocado con sus Padres en S. Lorenço debaxo del altar mayor con la solenidad y orden que el avia dispuesto que fue de la misma manera que entierra un frayle" (Vargas, 1995:387).

\footnotetext{
${ }^{2}$ El proceso de la buena muerte pasa por estos peldaños que nos muestra Martínez Gil (2000:619) “memento mori, resignación, lucidez, paciencia, piedad y devoción a los sacramentos de la iglesia (...) se enaltecen la castidad, la humildad y la justicia"; en este mismo sentido Pacheco (2005) subraya que se mencionan cuestiones referidas al entierro y a la escatología, siendo su tema central la agonía.
} 
A tal efecto -ante la gravedad e inminencia de la muerte- comenzaban a llegar a palacio las reliquias de todos los Santos de su devoción y a los que se reconocen cualidades milagrosas, traslados que se hacían desplegando un gran aparato ceremonial, acompañadas por cortejos de religiosos (Varela, 1990). Al mismo tiempo sus súbditos, en iglesias a lo largo y ancho del reino, comenzaban a rogar por su curación.

Producido el óbito en la Cámara Real en presencia de clérigos y cargos palaciegos, "el presidente del Consejo de Castilla, el mayordomo mayor y el sumiller de corps, llevaban el testamento cerrado al príncipe heredero ${ }^{3}$ y le pedían licencia para poder abrirlo" (Rodriguez Villa, 1918:151) y poder comenzar con los trámites del funeral regio.

\subsubsection{Exposición del cadáver}

Tres días ${ }^{4}$ estará expuesto el cuerpo del monarca en el Salón Grande -Salón Dorado- del Alcázar, para ser honrado y contemplado por sus súbditos, sean estos de cualquier condición, aunque la mejor condición otorgará siempre un mejor puesto, como veremos en el epígrafe siguiente dedicado a los "actores" de estas ceremonias. Durante la exposición del cadáver: su rostro y vestimenta ${ }^{5}$, así como las insignias y símbolos del poder real (Soto Caba, 1992), son visibles a todos, incluso al público general -a partir de Felipe IV- lo que produjo algún que otro altercado ya que "la muchedumbre arramblaba con toda clase de objetos: mantos, lienzos (...) peleándose por obtener un mejor lugar desde el que satisfacer su curiosidad" (Varela, 1990:86).

\subsubsection{Traslación al Panteón Real en San Lorenzo de El Escorial}

El nuevo monarca daba las instrucciones pertinentes sobre día y hora de la traslación del cadáver de su antecesor a su destino final en el panteón real, la "gigantesca capellanía que proporcionaba un privilegiado ${ }^{6}$ y privado lugar de enterramiento a la familia real y un gran cúmulo de sufragios por sus almas" (Martínez Gil, 2000:612). El traslado se verificaba transcurridos los tres días de exposición y en horario vespertino. Elegir el horario nocturno

\footnotetext{
${ }^{3}$ Que ya era rey al haber fallecido su padre, aunque no se hubiese alzado aún el pendón, cosa que sucedería en el plazo de unas semanas; el testamento contenía las previsiones mencionadas.

${ }^{4}$ Los mismos que dicen los Evangelios estuvo Jesús en el sepulcro y que señala Varela (1990:85) podría ser "el periodo de purgatorio [del rey] hasta su resurrección (...) a la gloria eterna".

${ }^{5}$ Los Austrias mayores fueron amortajados con hábitos de órdenes religiosas (al portarlas conseguían indulgencias); a Felipe IV le expusieron con todas sus galas.

${ }^{6}$ El diseño de la cripta lo hizo Felipe IV, en ella descansan en el lado del evangelio las urnas de los reyes; y en el de la epístola las reinas (Martínez Gil, 2000).
} 
tiene la finalidad de resaltar el impresionante cortejo -acompañado de música y velas- que acompañará el cadáver del rey difunto desde Madrid a El Escorial, donde llegará a primera hora de la mañana, para ser enterrado ${ }^{7}$ a mediodía.

Subraya Varela (1990:91) como este horario se ajusta -metafóricamente- a "los pasos del recorrido ultramundado del rey: cuerpo y alma, muerte y resurrección" que además -y de una forma ritual- indican que un astro se oculta -el rey muerto- $y$ otro renace, su sucesor.

\subsubsection{Honras fúnebres}

Transcurrido un periodo de tiempo desde el traslado a El Escorial tienen lugar las honras fúnebres, tanto en la Corte como en el resto de ciudades del reino. La ceremonia de honras más importante es la que se celebra en la ciudad sede de la Corte, aunque el aparato ceremonial que llevan a cabo otras ciudades no se queda atrás. En Madrid hay dos espacios fundamentales para esta celebración: el convento de San Jerónimo y el de la Encarnación; el primero de ellos fue utilizado tradicionalmente por los Austrias mayores, siendo el de la Encarnación el elegido por Felipe IV.

Es en este apartado, el de las honras, y en su misa de Requiem, donde los mensajes de poder real se ponen de manifiesto. Desde la decoración del espacio a la distribución de los distintos personajes de la Corte dentro del mismo, pasando por las oraciones fúnebres y los sermones, todo se dispone para la exaltación de la figura del rey muerto, la de su sucesor y la de una dinastía garante de la Fe.

\subsection{Ab ultima aeternitas ${ }^{8}$}

¿Cómo sacarle el máximo partido a esa muerte?: Escenificándola. Se necesitan: escenario, actores, guion y público (y para saber si ha tenido éxito, habrá que ver su repercusión en los medios de la época, las relaciones). Hay tres escenarios: la casa (palacio); la calle (los cortejos) y la iglesia (entierro y honras). Los actores: la nobleza, los cargos de la Corte y los eclesiásticos. El guion era el establecido en las Etiquetas de Felipe II y Felipe IV, en los libros de exequias y en los testamentos reales, donde daban indicaciones precisas al respecto. Mención especial merecen los libros de exequias, auténtico programa para un organizador de eventos del XVI-XVII, en ellos se recogen en distintos capítulos: la agonía, muerte y

\footnotetext{
${ }^{7}$ Entregado su cuerpo al abad del monasterio.

${ }^{8}$ A partir de la última (hora), la eternidad.
} 
entierro del difunto; sus virtudes; el detalle organizativo de las honras; descripción de la decoración; listado de asistentes; los actos litúrgicos y los sermones predicados (Allo y Llorente, 2004).

\subsubsection{El escenario y los actores}

\section{(a) La cámara}

La cámara real, con la decoración de reliquias ${ }^{9}$ que se han ido trayendo al objeto de obtener sus favores religiosos, tiene, en virtud de esta decoración, el aspecto de una capilla; es el espacio en el que tendrán lugar una serie de ceremonias -eminentemente religiosasconducentes a preparar al rey agonizante para el paso a la vida eterna. En la cámara al monarca se le administrarán viático y extremaunción por los más altos cargos eclesiásticos de la Corte. Varela (1990) citando a Rodríguez Monforte (1666) detalla el espectáculo público que supuso la administración del viático y de los Santos Oleos a Felipe IV. Dos ceremonias en las que el protocolo estuvo muy presente por el rango y el orden en el que desfilaron en cortejo los altos personajes de la corte y por el de los que estaban presentes en la real cámara cuando se produjo.

\section{(b) Capilla ardiente}

La capilla ardiente se montaba en el Salón Grande del Alcázar -también conocido como el Salón Dorado- que se decoraba convenientemente para albergar el cadáver y distintos altares desde los que se dirían misas y responsos. Este espacio se transforma también en templo y en él el cuerpo del rey muerto se trata como una reliquia (Soto Caba, 1992).

Rodriguez Villa (1918) da cuenta de cómo se organizaba ese espacio cuyo croquis se recoge en la llustración n01: se montaba una tarima con varias gradas, alfombrada de negro con bordados de oro y plata sobre la que se instalaba una cama con dosel (1) ${ }^{10}$ Varela (1990) habla de otros supuestos en los que lo que se situaba en la tarima era directamente el ataúd ligeramente inclinado para poder ser visto con facilidad. Subraya además este autor que el espacio estaba decorado con los cuadros de todos los reyes de la dinastía que había

\footnotetext{
${ }^{9}$ La presencia de las reliquias, como apunta Soto Caba (1992), con su carga simbólica, transforman la real cámara en una capilla

${ }^{10} \mathrm{El}$ dosel es uno de los primeros símbolos del poder, el rey ha ido bajo dosel en los fastos ocurridos a lo largo de su reinado, por tanto bajo dosel está su cuerpo muerto (Varela, 1990 y Soto Caba, 1992)
} 
precedido al monarca finado (nunca con el retrato del propio monarca, ya que se encontraba allí, de cuerpo presente) lo que enviaba ya de por sí el mensaje de la grandeza y majestad de los Habsburgo.

Alrededor de la tarima se instalaban distintos altares (A), uno a los pies de la tarima, desde donde se dirían las mismas de pontifical (3) ${ }^{11}$ (con su lado de la epístola (5) y lado del evangelio (4) ${ }^{12}$, en el que se instalaban bancos -para los Grandes (7) y Capellanes (8) y el asiento destinado al mayordomo mayor (6); quienes asistirían a los oficios en aquel espacio) y otros seis alrededor para las misas rezadas (A). Cerrando la composición, el coro (9). Para que se pudiera contemplar el espectáculo se situaba una valla perimetral, que facilitaba la deambulación al tiempo que impedía el acceso.

Ilustración 1: Detalle de la organización del espacio en el Salón Real

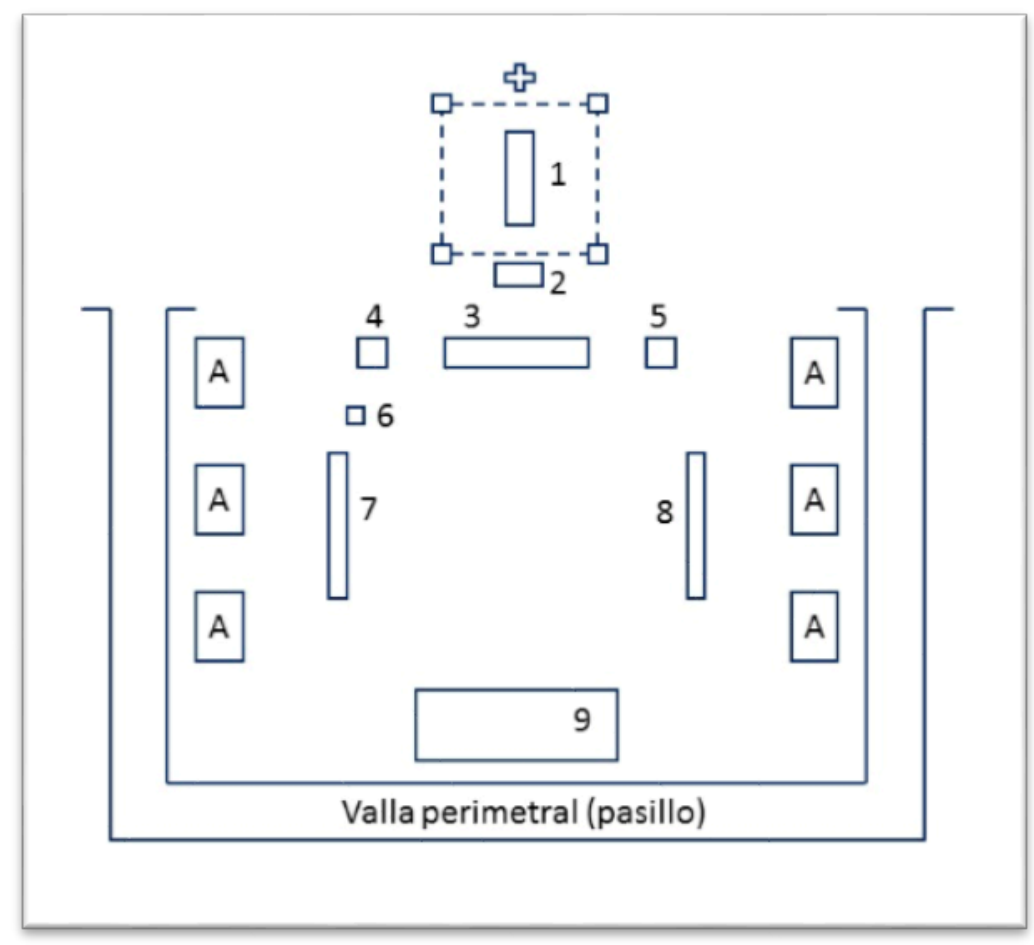

Fuente: Elaboración propia sobre descripción de Rodríguez Villa

Solo personajes de la corte y eclesiásticos participaban en estas ceremonias (incluidos los Monteros de Espinosa, que velaban el cadáver). El mensaje o los mensajes que transmitían las ordenaciones: a mayor proximidad mayor importancia; quien gozaba del favor real; quién

\footnotetext{
${ }^{11}$ La misa solemne celebrada por un obispo o por un prelado que goza del privilegio de mitra y báculo.

12 Soto Caba (1992) ve en esta mención "el parangón que el salón de palacio tenía con el interior de la iglesia
} (35) 
apoyaba a la dinastía y, por encima de todo ello, el papel de la monarquía en la expansión de la fe.

(c) San Lorenzo de El Escorial

La traslación del cadáver a su morada definitiva en el panteón real, daba pie a uno de los espectáculos más vistosos y sobrecogedores: el cortejo fúnebre, todo un acontecimiento público. El cortejo ofrecía una composición como la que podemos ver -muy esquematizadaen la llustración no 2. El féretro con el cadáver (9) salía de la casa (el Palacio) para ir recorriendo las calles y caminos que cubrían las aproximadamente 10 leguas entre Madrid y El Escorial. Cortejo vistoso por la calidad de quienes acompañaban el féretro e impresionante, por la vestimenta -van de luto- y la cantidad de hachas encendidas como las que portan los pajes que rodean el féretro (10), que a las horas de la noche en las que transitaba, a buen seguro sobrecogería los espectadores.

Los partícipes (en dos filas de 12 individuos ${ }^{13}$ por categoría) vuelven a ser oficios de la Corte (2, 7, 10 y 14 y el mayordomo mayor (12), Grandes de España (8), Eclesiásticos (1, 5, y el prelado oficiante 13) y las distintas Guardias de Palacio $(3,6,11,15$ y 16$)$, porque hay que mantener a los espectadores en su sitio, para que no resten brillantez al acto.

Ilustración 2: Detalle de un cortejo fúnebre

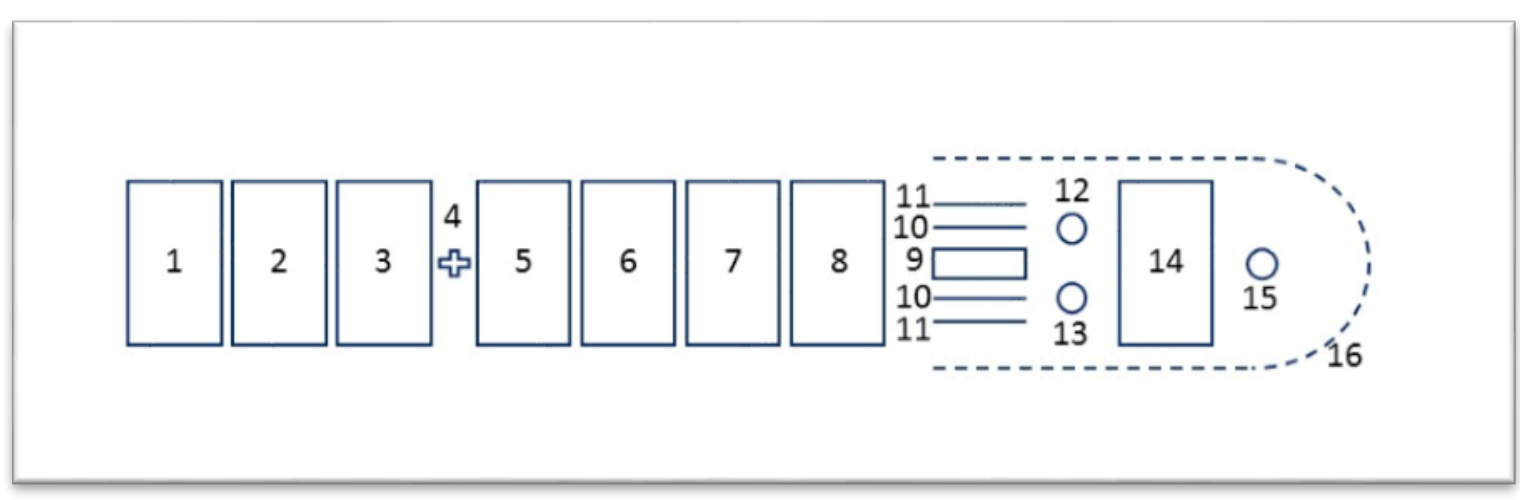

Fuente: Elaboración propia sobre descripción de Rodríguez Villa

Destaca Soto Caba (1992) la similitud de estos traslados con aquellos otros que desde distintas ciudades fueron trayendo las reliquias de Santos para su veneración. "El traslado de reliquias $^{14}$, es una liturgia funeraria, pero triunfal, como triunfal era también la comitiva

\footnotetext{
${ }^{13}$ Doce, como los apóstoles. De nuevo la relación de la dinastía con la fe.

${ }^{14}$ Como curiosidad: las primeras reliquias que llegaron al monasterio fueron las de los Santos Justo y Pastor, procedentes de Huesca, así lo señala Fray José de Sigüenza en su Historia del Monasterio del Escorial (1602).
} 
fúnebre de los reyes haciendo su entrada en la morada final. (...) en este sentido, los soberanos fueron tratados a la manera de reliquias (...)" (Soto Caba, 1992:38).

Una vez llegaba la comitiva al monasterio tenía lugar la ceremonia de entrega del cadáver a la comunidad de religiosos, que salía a recibirlo al pórtico; el oficio de difuntos, en la iglesia; la identificación del cadáver (previa apertura del féretro) y la entrega del mismo al abad del monasterio. El féretro que iba pasando de un espacio a otro para los distintos oficios era portado solo por los altos oficiales de la Corte y los Grandes de España, pero a la bóveda lo bajaban los Monteros de Espinosa.

Los espacios a utilizar en el monasterio eran: el pórtico, en el que había un bufete cubierto de brocado sobre el que se situaba el féretro; la iglesia, en la que el féretro se situaba sobre un túmulo; la antesacristía, donde volvía a situarse el féretro sobre un bufete y la puerta de la bóveda, donde el féretro pasaba a los Monteros de Espinosa quienes lo llevaban "hasta el sitio donde había de quedar" (Rodríguez Villa, 1918:153).

El mensaje en el monasterio, gran mausoleo, panteón real, lo resume Varela (1990:25) en esta frase: “El cadáver y la efigie (...) del rey aparecían en El Escorial para proclamar la inmortalidad y el carácter divino de la realeza".

\section{(d) San Jerónimo o la Encarnación}

La iglesia, en la que semanas después de la entrega del cadáver al abad del monasterio se producía la ceremonia de honras fúnebres, se decoraba tanto en el exterior como en el interior: con "telas de oro, damasco y terciopelos negros" y la nave hasta la puerta con paños negros. El suelo y los bancos de los grandes "de bayetas"15 (Rodríguez Villa, 1918:151). El luto se hace presente, los asistentes están allí para celebrar un acto religioso muy solemne en recuerdo del rey fallecido.

El exterior del templo aparece enlutado, para ello se tapa "con colgaduras negras (...) jeroglíficos y epitafios latinos (...) arquitecturas pintadas (...) bajo doseles también negros se colocan las armas reales o los emblemas de la corporación organizadora" Varela (1990:109). Siguiendo a este mismo autor y a Rodríguez Villa (1918) accedemos al templo por la nave central, el lugar de tránsito del templo, que aparece cubierta de paños negros (bancos y

\footnotetext{
${ }^{15}$ El término "bayeta" en el Diccionario de Autoridades (1726-1739) aparece definido de la siguiente manera: "Tela de lana mui floxa y rala, de ancho de dos varas lo mas regular, que sirve para vestídos largos de Eclesiásticos, mantillas de mugéres, y otros usos. Háilas de todas colóres, blancas, verdes, negras".
} 
suelo incluidos) sirviendo la calidad del paño para mostrar el rango de quien lo ocupa, a mayor calidad, mayor rango (el mensaje para el que lo observa es el de mayor cercanía al altar, mayor poder y mayor apoyo a la dinastía) y también "cuadros alusivos a sus hechos del monarca- más sobresalientes" así como "medallones, cornucopias, jeroglíficos, calaveras" (Varela, 1990:110) destinados a centrar la atención de los asistentes en la grandeza de aquel en cuyo recuerdo se realizaba la ceremonia. Durante esta época es de gran importancia la emblemática, en la que "el juego del ingenio" se convirtió en un elemento de singular relieve en el discurso moralizante de las arquitecturas efímeras" (Pizarro, 1985:47); se invitaba al espectador a desentrañar la clave -manifiesta y oculta- de jeroglíficos y alegorías.

Atravesando la nave central se llegaba al altar mayor, que también se cubría con cortinas negras, allí, en la capilla mayor - según descripción que hace Rodríguez Villa (1918) en las Etiquetas de la Casa de Austria- se montaba un túmulo con columnas y techado, que se adornaba con trofeos; en su base se colocaba una grada de cuatro o cinco escalones sobre la que descansaba el catafalco. Se ponía una cruz a la cabecera y una almohada a los pies, sobre la que descansaban: corona, cetro, collar del Toisón y la espada. "Templos y túmulos fueron ornados mediante inscripciones, jeroglíficos y alegorías, pero más allá de la mera función decorativa, cumplieron una importante misión comunicativa" (León, 2010; 30) que veremos en los siguientes párrafos. Situado en el centro del crucero es el lugar donde se centrarán las miradas y en el que "no había un cadáver corrupto, sino los símbolos de lo que no muere y un monumento ascendente que casi llega a tocar las bóvedas" (Martínez Gil, 2000:631).

Rodríguez Villa (1918) describe un monumento funerario -túmulo- básico, descripción que ha servido de base para elaborar la llustración $n$ 우; pero esa pieza de arquitectura efímera, que domina la parte principal del edificio religioso, y que en grabados ha llegado hasta nosotros, dista de ser algo sencillo.

A medida que aumenta el poder político de la Casa de Austria según avanza el siglo XVI, el túmulo se va transformando adquiriendo un carácter imponente en tamaño y extremo en decoración "parlante". El túmulo va ganando en dimensiones -llegando incluso a tocar el cimborrio de la catedral Sevillana, en el caso del que allí se erigió para honrar a Felipe II (Collado, 2005)- y complejidad -está cubierto de "adornos, figuras, nichos, cornisas, columnas (...) que forman un "complicado artefacto cuajado de significaciones múltiples (...) 
que desde su imponente altura, parece querer enseñar a los espectadores una variedad de lecciones morales" (Varela, 1990:113) con una sola finalidad: mostrar al espectador el poder del rey y, por ende, el de la dinastía, justificando que gobiernan los mejores por sus cualidades morales y virtudes cristianas.

\section{Ilustración 3: Simulación de un túmulo funerario}

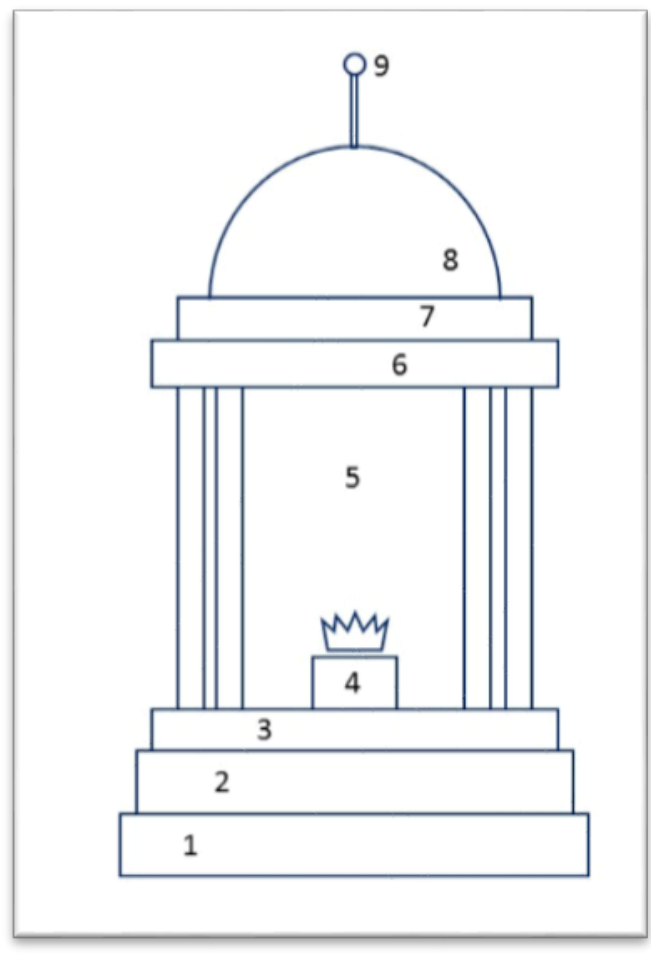

Fuente: Elaboración propia

La estructura del túmulo va en orden ascendente y sigue el ciclo vital - siempre glorioso de aquel a quien se dedica, porque tiene como base la gloria de quienes le precedieron, de su dinastía; predecesores que están presentes a través de escudos, simbología -y/o emblemática- que los representaban (1). Sobre esa base se iban superponiendo niveles en los que aparecían las hazañas político-militares (batallas, conquista de territorios) del rey y que formaban parte de su fama (2). Con este fundamento en aspectos del ejercicio de gobierno y las virtudes políticas que poseía el príncipe (prudencia, justicia, fortaleza y templanza) y que habían contribuido a sus éxitos políticos (3), la fama se transforma en “inmortalidad concebida desde los aspectos terrenales" (León, 2010: 388).

En otro nivel a parecía el triunfo de la muerte, el cadáver del rey ya no estaba presente, pero se representaba mediante una urna y los atributos de la monarquía (4); este nivel estaba entre columnas y cerrado por arriba, a modo de palio o dosel (5). Más arriba las virtudes teologales (fe esperanza y caridad) que le llevarían a la vida eterna (6 y 7). 
Sobre todo ello $-\mathrm{y}$ a modo de cierre- el triunfo que, sobre la muerte, suponen la gloria alcanzada al abandonar el mundo (9) -la inmortalidad de su alma- y la gloria humana (8), que se manifiesta en la continuidad de la dinastía a la que ha engrandecido con su legado y que de este modo renueva sus votos con la Iglesia Católica.

Esa elevación o escalamiento de lo terreno a lo divino, lo vemos en esta descripción que hace Vicente Lleó del túmulo de Felipe II en el prólogo del libro de título homólogo de Francisco Collado: "El discurso del conjunto funerario describía pues una vía ascensional que llevaría al monarca, desde las grandes hazañas de su reinado, a sus virtudes como gobernante, a sus virtudes como persona, a la intercesión celestial y, finalmente, a la Gloria" (Collado, 2005:13)

\subsubsection{El público}

Los súbditos estaban de luto, se suspendían las fiestas públicas por espacio de cuarenta días y la muerte del rey imponía vestir de luto ${ }^{16}$ a todas las capas de la sociedad durante seis meses, pero hasta en esto había diferencias, no vestía prendas de igual calidad un noble que un sirviente (Varela, 1990 y Valenzuela, 2001).

El pueblo recibe la comunicación de la muerte del rey a través del sonido de las campanas de las iglesias, la forma de comunicación más rápida de la época. Si moría el rey sonaban tocando a clamores- todas las campanas de la torre en la catedral, y no lo hacían solo una vez, "sonaban durante nueve días y a las mismas horas -6 y 7 am, 12 y 13 pm y 8 y 9 pmademás sonaban también los días de las honras y su víspera". (Martínez Gil: 2000:418). Para los ciudadanos era imposible olvidarse de que el rey había muerto, ya que el sonido a muerte de las campanas era la "contaminación acústica" de la época.

La función de los habitantes del reino era la de asistir, como meros espectadores y desde el lugar que por su condición les correspondía, a los faustos organizados para honrar al rey. Rezaban por su recuperación durante la agonía y por su alma a partir de la muerte, ya que la salvación del alma del rey era señal de que ellos se salvarían también en el bien entendido que "el premio (la salvación) otorgado a la cabeza (el rey) también alcanzaría a los miembros del cuerpo social" (Martínez Gil, 2000:622). Ese premio es un signo de alegría,

\footnotetext{
${ }^{16}$ Sobre los tipos de vestimenta de luto, quienes la llevaban y por quienes se llevaba, véase la Ley II, T XII, del L VI de la Novisima Recopilación
} 
porque para el devoto cristiano "el final de la vida mortal (es) el comienzo de la vida eterna" (Gallego, 1985:120).

Contemplaban a distancia lo que allí sucedía, no tenían una participación activa, como la aristocracia o los eclesiásticos -actores, junto con el fallecido- se situaban apiñados tras la valla perimetral que veíamos en la llustración 1, o en "corredores, ventanas de la iglesia y lugares donde no estorbaran" (Soto Caba, 1992:43).

Las clases altas se blindaban contra la posibilidad de "excesos de una multitud enfervorecida por el espectáculo macabro" (Soto Caba, 1992:42), frenando sus impulsos desestabilizadores, para ello levantan vallas, rejas, etc. y la presencia del cuerpo de guardia es grande y constante en todos los ceremoniales.

\section{CONCLUSIONES}

La muerte no tiene un carácter igualador, por mucho que el esqueleto y la guadaña, figuras simbólicas que adornaban con profusión los túmulos de los Austrias, así lo pretendiesen. La muerte del poderoso era distinta a la de sus súbditos, porque el poderoso -y quienes le rodeaban- podían utilizarla en su propio beneficio mediante el montaje de un ceremonial majestuoso, con unos objetivos de comunicación muy claros, para el cual tenían una fuente -casi- inagotable de recursos.

Esos objetivos de comunicación presentes en las ceremonias descritas tenían como finalidad en primer lugar: perpetuar la presencia del rey, para lo cual se llegaba a sacralizar su figura que conseguía así -en teoría- la gloria eterna, la inmortalidad del alma; la gloria terrenal estaba fundamentada en su fama, en el respeto que le prodigaban los que le rodeaban y en la perpetua morada eterna que le albergaría (y le alberga). La terrenal era fácil conseguirla, solo había que magnificar su figura.

En segundo lugar estaba el de dar fe del poder de la dinastía y la fidelidad de la nobleza. No hay duda del poder, aún ejercido de forma coercitiva, que tenía la dinastía (era obligatorio realizar este tipo de ceremonias, era obligatorio vestir de luto y era obligatorio suspender las fiestas y representaciones, etc., lo que hacía del duelo un sentimiento obligatorio). Este poder necesitaba de la fidelidad de la nobleza presente en los actos de funeral. Su presencia en los principales lugares, en los más próximos al finado y a su sucesor, convenientemente ordenada y separada del pueblo, estaba recogida en el estricto protocolo que regulaba los actos y suponía un apoyo para el sucesor. 
El compromiso del fallecido y su sucesor con la iglesia católica quedaba patente a lo largo de todas las ceremonias, no solo por la gran presencia de clérigos en todos los actos, sino porque el palacio se convertía en capilla e iglesia. La cámara en capilla, allí fallece el rey rodeado de reliquias de santos, y el salón en iglesia, con siete altares desde donde se dicen misas de cuerpo presente. $Y$ además el rey ha tenido una buena muerte y su alma se ha salvado, lo cual contribuye -mediante el ejemplo- a la expansión de la religión.

Por último estas ceremonias -aunque obligatorias como hemos visto- contribuyen a atar los lazos con los súbditos. A través de estas ceremonias magníficas, sobrecogedoras, impresionantes; de estas obras de teatro con actores, decorado y guion, el pueblo se sentía partícipe, aún a distancia como en toda obra de teatro desde donde tenía una buena vista del conjunto, y en ese lugar, de pie y apretujado vivía las emociones de los actores, orgulloso de pertenecer a una monarquía poderosa.

\section{BIBLIOGRAFÍA}

ALLO A. y ESTEBAN J.F. (2004): El estudio de las exequias reales de la monarquía hispana. Siglos XVI, XVII y XVIII, Artigrama, 19, pgs. 39-94.

COLLADO, F. (2005): Descripción del túmulo de Felipe II. Sevilla. Servicio de publicaciones del Ayuntamiento de Sevilla.

DE SIGÜENZA, J. (1881): Historia primitiva y exacta del Monasterio del Escorial. Madrid. Imprenta y fundición de M. Tello (ed. facsímil).

GALLEGO, J. (1985): Aspectos emblemáticos en las Reales Exequias españolas de la Casa de Austria. Madrid. Fundación Lázaro Galdiano.

HEIMANN, H.D., KNIPPSCHILD, S. y MíNGUEZ, V. (eds) (2004): Ceremoniales, ritos y representación del poder. Castellón. Universitat Jaume I.

LEÓN PÉREZ, D. (2010): Las exequias reales en Madrid durante el primer tercio del siglo XVIII: corte y villa. León. Área de publicaciones de la Universidad de León.

MARTínEZ GIL, F. (2000): Muerte y sociedad en la España de los Austrias. Cuenca. Servicio de publicaciones de la Universidad de Castilla la Mancha.

PACHECO, F. (2004): El túmulo de la reina doña Ana de Austria. Madrid. Laberinto.

PIZZARRO GÓMEZ, F.J. (1985): Astrología, emblemática y arte efímero. Fundación Lázaro Galdiano.

RODRIGUEZ VILLA, A. (1915): Etiquetas de la Casa de Austria. Madrid. Jaime Ratés (disponible en http://bdh-rd.bne.es/viewer.vm?id=0000092539\&page=1)

SOTO CABA, V. (2002): Los catafalcos reales del barroco español. Madrid. UNED.

VALENZUELA, J. (2001): Las liturgias del poder. Celebraciones públicas y estrategias persuasivas en el Chile colonial (1606-1709). Chile. LOM Ediciones.

VARELA, J. (1990): La muerte del rey. El ceremonial funerario de la monarquía española 81500-1885). Madrid. Turner. 
VARGAS HIDALGO, R. (1995): Documentos inéditos sobre la muerte de Felipe II y la literatura fúnebre de los siglos XVI y XVII, Boletín de la Real Academia de la Historia, Tomo CXCII, pgs. 377-460.

Legislación:

Novissima Recopilación de las Leyes de España, disponible en la Biblioteca Virtual del Patrimonio Bibliográfico del Ministerio de Educación, Cultura y Deporte http://bvpb.mcu.es/es/consulta/registro.cmd?id=403945

(c) (i)

This work is licensed under a Creative Commons Attribution 3.0 Unported License 
